\title{
Febrile patients admitted to remote hospitals in Northeastern Kenya: seroprevalence, risk factors and a clinical prediction tool for Q-Fever
}

\author{
J. Njeru ${ }^{1,2,3^{*}}$, K. Henning ${ }^{1}$, M. W. Pletz ${ }^{2}$, R. Heller ${ }^{4}$, C. Forstner ${ }^{2,5}$, S. Kariuki ${ }^{3}$, E. M. Fèvre ${ }^{6,7}$ and H. Neubauer ${ }^{1}$
}

\begin{abstract}
Background: Q fever in Kenya is poorly reported and its surveillance is highly neglected. Standard empiric treatment for febrile patients admitted to hospitals is antimalarials or penicillin-based antibiotics, which have no activity against Coxiella burnetii. This study aimed to assess the seroprevalence and the predisposing risk factors for $\mathrm{Q}$ fever infection in febrile patients from a pastoralist population, and derive a model for clinical prediction of febrile patients with acute $\mathrm{Q}$ fever.

Methods: Epidemiological and clinical data were obtained from 1067 patients from Northeastern Kenya and their sera tested for lgG antibodies against Coxiella burnetii antigens by enzyme-linked-immunosorbent assay (ELISA), indirect immunofluorescence assay (IFA) and quantitative real-time PCR (qPCR). Logit models were built for risk factor analysis, and diagnostic prediction score generated and validated in two separate cohorts of patients.

Results: Overall 204 (19.1\%, 95 \% Cl: 16.8-21.6) sera were positive for lgG antibodies against phase I and/or phase II antigens or Coxiella burnetii IS1111 by qPCR. Acute Q fever was established in 173 (16.2 \%, $95 \%$ Cl: 14.1-18.7) patients. Q fever was not suspected by the treating clinicians in any of those patients, instead working diagnosis was fever of unknown origin or common tropical fevers. Exposure to cattle (adjusted odds ratio [aOR]: 2.09, $95 \% \mathrm{Cl}$ : 1.73-5.98), goats (aOR: 3.74, 95 \% Cl: 2.52-9.40), and animal slaughter (aOR: 1.78, 95 \% Cl: 1.09-2.91) were significant risk factors. Consumption of unpasteurized cattle milk (aOR: 2.49, 95 \% Cl: 1.48-4.21) and locally fermented milk products (aOR: 1.66, $95 \% \mathrm{Cl}: 1.19-4.37$ ) were dietary factors associated with seropositivity. Based on regression coefficients, we calculated a diagnostic score with a sensitivity $93.1 \%$ and specificity $76.1 \%$ at cut off value of 2.90 : fever $>14$ days $(+3.6)$, abdominal pain $(+0.8)$, respiratory tract infection $(+1.0)$ and diarrhoea $(-1.1)$.

Conclusion: $\mathrm{Q}$ fever is common in febrile Kenyan patients but underappreciated as a cause of community-acquired febrile illness. The utility of $\mathrm{Q}$ fever score and screening patients for the risky social-economic and dietary practices can provide a valuable tool to clinicians in identifying patients to strongly consider for detailed $\mathrm{Q}$ fever investigation and follow up on admission, and making therapeutic decisions.
\end{abstract}

Keywords: Seroprevalence, Epidemiology, Coxiella burnetii, Q fever, Kenya

\footnotetext{
* Correspondence: John.Njeru@fli.bund.de

${ }^{1}$ Institute of Bacterial Infections and Zoonoses, Friedrich-Loeffler-Institut,

07743 Jena, Germany

${ }^{2}$ Center for Infectious Diseases and Infection Control, Jena University

Hospital, 07740 Jena, Germany

Full list of author information is available at the end of the article
} 


\section{Background}

$\mathrm{Q}$ fever is an acute (on occasion chronic) zoonotic disease of global public health importance. The disease is caused by the obligate Gram-negative bacterium Coxiella (C.) burnetii [1]. Domestic animals such as cattle, sheep and goats are the main reservoirs of $C$. burnetii which can infect a large variety of animals, humans, and arthropods [2]. Infection in humans usually occurs by inhalation of contaminated aerosols, consumption of contaminated unpasteurized dairy products, direct contact with contaminated milk, urine, feces, or semen of infected animals, and tick bites [3]. Clinical presentation is nonspecific and highly variable ranging from asymptomatic infection (60\%) or self-limiting febrile illness associated with fatigue, headache, general malaise, myalgia, arthralgia, to atypical pneumonia (rapidly progressive courses may occur) and/or hepatitis. Less frequent manifestations include endocarditis, osteomyelitis and aseptic meningitis. About 1-2 \% of acute symptomatic cases may develop chronic disease $[4,5]$. Q fever is considered to be an occupational disease of people who have intimate contact with animals or their products such as veterinarians, farmers, abattoir workers, and laboratory workers $[4,6]$.

Acute $\mathrm{Q}$ fever in humans is confirmed when a patient present with clinically compatible symptoms and detection of the $C$. burnetii by at least one of the following diagnostic tests; cultivation, detection of $C$. burnetii DNA from any clinical specimens (usually blood or respiratory secretions), detection of C. burnetii in a clinical specimen by immunohistochemistry (IHC), seroconversion or a fourfold increase from non-negative titer sera [7]. In the absence of positive culture, IHC or PCR results, and when acute and convalescent serum samples cannot be obtained, elevated phase II IgG antibodies level by ELISA or positive indirect immunofluorescence assay (IFA) (IgG phase II $\geq 1: 128$ ) in a patient who has been ill longer than 1 week is laboratory supportive of acute Q fever infection while IgG phase I titer $\geq 1: 800$ is seen in chronic patients [2, 7-9].

$\mathrm{Q}$ fever is a notifiable disease in many developed countries, but it is poorly reported in sub-Saharan Africa and its surveillance is highly neglected [10]. Available reports from previous studies show remarkable high seroprevalence in the African countries with intensive livestock production systems [11-13]. Pastoralist communities are particularly at high risk of pathogen exposure because of their itinerant lifestyle and highly conserved traditions that make them more likely to consume unboiled milk products and raw meat from infected animals. They are also less likely to protect themselves when handling animal birth products and vaginal discharges after abortion or fullterm parturition $[14,15]$. Despite these, few studies have investigated in detail the risk factors or the reasons for variation of prevalence in the diverse agroecological African settings [10]. This lack of attention is mainly caused by lack of data and the perceived low clinical relevance of $\mathrm{Q}$ fever in relation to other endemic fevers [16, 17].

In Kenya, Q fever in humans was first reported in hospitalized patients in 1950s [18-20]. A serosurvey by Vanek and Thimm, (1976) detected seroprevalences ranging from 10 to $35.8 \%$ in patients from five provinces of Kenya [21]. An outbreak of Q fever involving safari travelers in a game park was described in 2000 in which 4 (8\%) of fifty travelers contracted the disease [22]. A recent study in a rural hospital in western Kenya demonstrated IgG antibodies to C. burnetii antigens in $30.9 \%$ of acute febrile illness (AFI) patients. In addition, acute $\mathrm{Q}$ fever was detected in $3 \%$ of patients diagnosed with acute lower respiratory infections (ALRI) in the same hospital [17]. Among domestic animals in Kenya, prevalence of Coxiella antibodies was reported ranging from 7.4 to $51.1 \%$ in cattle, 6.7 to $20 \%$ in sheep, 20 to $40 \%$ in goats, and 20 to $46 \%$ in camels [17, 20, 21, 23].

There is emerging evidence of $C$. burnetii as a cause of non-malaria febrile illness and community acquired pneumonia in many African countries including Kenya [16, 17, 24-27]. Many etiologies of febrile illnesses are difficult to distinguish from one another clinically and reliable laboratory diagnostic facilities are often limited in developing countries, thus clinical management of such illness is often driven by syndrome-based local guidelines employing empiric treatment [28]. This makes timely and accurate diagnosis or management of the neglected diseases such Q fever an important challenge to clinicians [29]. A systematically collected data on $\mathrm{Q}$ fever burden estimates and risk factor analysis is needed to support development of targeted interventional control policies. In addition, a simple clinical algorithm with high diagnostic sensitivity and specificity remains an important tool for timely detection, and prevention of morbidity associated with $Q$ fever in regions where laboratory facilities are lacking.

This study aimed to estimate the seroprevalence of $Q$ fever in patients with febrile illness seeking treatment at two hospitals in the Northeastern province of Kenya and investigate the risk factors for seropositivity. We also evaluated the usefulness of clinical signs and symptoms in predicting $Q$ fever outcome. We hypothesized that a clinical prediction score system with high diagnostic accuracy would be of benefit to clinicians who work in resource scarce settings in making decisions on febrile patients to strongly consider for $\mathrm{Q}$ fever investigation during initial diagnosis, and when making empirical therapeutic decisions. This hypothesis was tested using derivation and validation cohorts. 


\section{Methods}

\section{Study area}

The study was conducted at Garissa Provincial Hospital (GPH) and Wajir District Hospital (WDH) of Northeastern province of Kenya (Fig. 1). GPH has 224 beds and serves an estimated population of 623,060 individuals, whereas WDH has 120 beds serving about 661,941 individuals. These health facilities are also the main referral hospitals of the Garissa and Wajir counties respectively. The province has an arid and semiarid lands (ASAL) climate and is almost exclusively inhabited by the Somali ethnic groups who are predominantly nomadic pastoralists. Livestock keeping is the main economic activity in the region. The common diet for the communities in the province is meat and milk $[15,30]$.

Drinking of raw milk is common in this population due to deep-rooted cultural traditions. It is believed that boiling milk reduces the nutritional value of milk. Milk is also mixed from several animals in common containers. From this milk, fermented products (local name 'susac') are prepared. Susac would then be sold at the nearest open market places and nomadic camp sites $[15,31]$. This province was selected because public health support and disease surveillance has been extremely limited and outbreaks of re-emerging diseases have been reported in the province before [32-34].

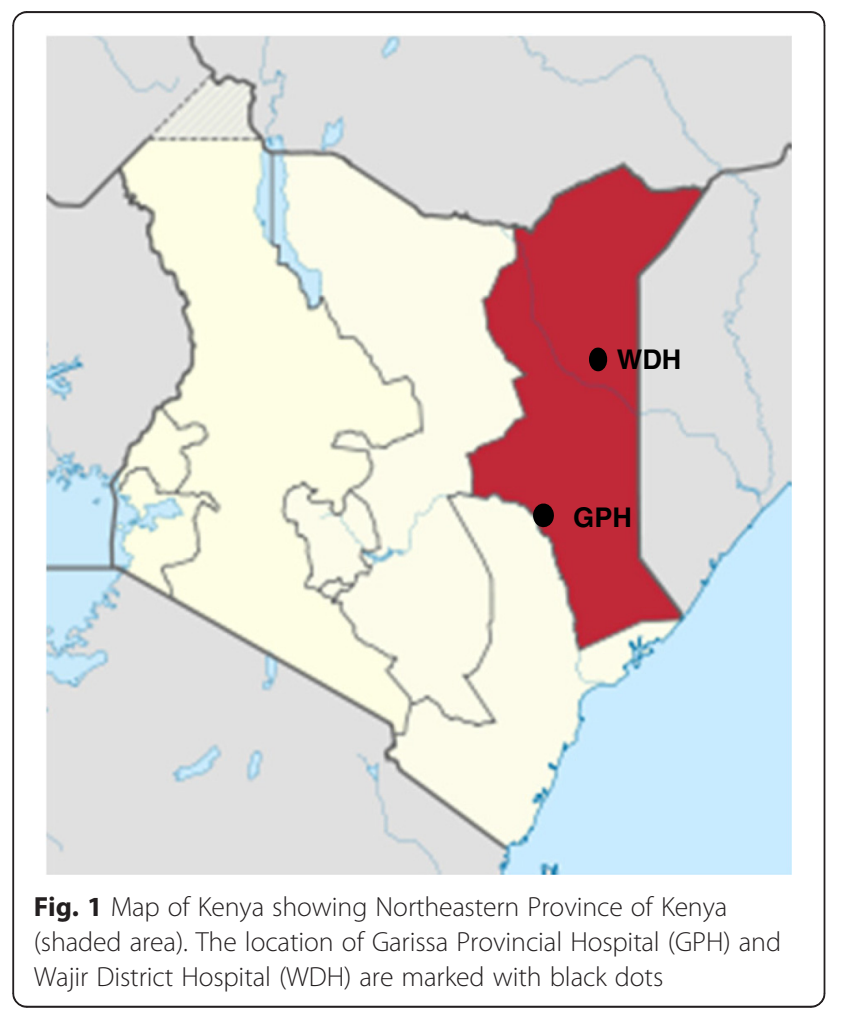

\section{Study participants and procedures}

The hospital-based study was conducted between June 2014 and January 2015. Acute febrile patients presenting to the outpatient departments of the two hospitals were systematically assessed for enrollment. The inclusion criteria were: a clinical history of acute febrile illness (AFI) characterized by fever (higher than or equal to $38{ }^{\circ} \mathrm{C}$ ) and at least one of the following clinical symptoms: headache, chills, myalgia, arthralgia, general body malaise, and acute lower respiratory illness (ALRI). ALRI was defined as new onset of cough, difficulties when breathing or chest pain and fever [17]. A study clinician then collected demographic information, obtained clinical history and performed physical examination of the enrolled participants. The clinical diagnosis made by the attending hospital clinician was also recorded. Exclusion criteria were: patients younger than 18 years not accompanied by a guardian or parents, patients who had an already established diagnosis and those who were severely sick and were considered not able to provide informed consent. Patients who declined to participate were also excluded.

\section{Sample and data collection}

Demographic information and data on putative socialeconomic and dietary characteristics of the patients were collected using pre-tested questionnaires. Risk factors were assessed in form of a mix of closed- and open-ended questions including the following data: (a) living in a livestock keeping household/nomad camp or involvement in animal husbandry activities for at least 2 days a week (hereafter referred to as 'regular contact with animals'), (b) animal species involved, and (c) the type of contact with animals or their products i.e. help in animal parturition, contact with aborted materials, grazing animals, livestock trade, handling raw milk, and animal slaughter. Participants were also asked if they shared their house with animals and if they were involved in manure preparation. The food variables assessed were: (i) consumption of raw milk, (ii) locally fermented milk products (susac), (iii) drinking of animal blood and (iv) consumption of uncooked meat.

Following cleansing of the skin with isopropyl alcohol and povidone iodine, five milliliters of venous blood were collected aseptically into empty $10 \mathrm{ml}$ serum BD vacutainer tubes $^{\oplus}$ (Becton, Dickson and Company, USA). The blood samples were stored at room temperature for $45 \mathrm{~min}$ to allow blood clotting. The samples were then centrifuged at $2500 \mathrm{rpm}$ for $5 \mathrm{~min}$ and serum was separated. Sera were aliquoted into cryo-vials before shipping to Friedrich-Loeffler-Institut (FLI) for Q fever laboratory analysis. 


\section{Serological analysis}

Sera were analyzed for IgG antibodies against phase I and phase II antigens using serion ELISA classic test kits (Virion\Serion, Würzburg, Germany) and evaluated according to the manufacturers' recommendations. For phase I, samples with an optical density (OD) $>10 \%$ above OD of the cut-off sera were scored as positive, those with ODs $>10 \%$ below OD of the cut-off sere were considered as negative, in between samples were denoted as borderline. For phase II, the cut off value was calculated on the basis of the standard curve corrected by the mean of the extinction of the standard serum according to the manufacturers' instructions. A result of $<20 \mathrm{U} / \mathrm{ml}$ was regarded as negative, 20-30 U/ $\mathrm{ml}$ borderline, and $>30 \mathrm{U} / \mathrm{ml}$ as positive.

The seropositive samples and those with inconclusive results were confirmed with a commercial IFA for detection of IgG antibodies against C. burnetii phase I and phase II (Fuller Laboratories, USA). The assay titers were started at 1:16 and results interpreted according to the manufacturers' instructions. Samples with C. burnetii phase II antibodies titers of $>1: 128$ were scored as acute Q fever positive, while those with phase I antibodies titers of $\geq 1: 800$ were regarded as positive for chronic $Q$ fever. The samples that were found to be equivocal in the repeat tests were re-tested at the $\mathrm{Q}$ fever consulting laboratory Baden-Wurttemberg, State Health Office, Germany.

\section{DNA extraction from samples}

DNA isolation was done using the High Pure PCR Template preparation commercial Kit ${ }^{\text {tax }}$ (Roche Diagnostics, Germany) according to the manufacturer's instructions. Purity and concentration of DNA was tested using a Nano Drop ND-1000 UV-vis spectrophotometer (Nano Drop Technologies, Wilmington, USA), and DNA samples were stored at $-20{ }^{\circ} \mathrm{C}$ until analyzed.

\section{Quantitative Real-time PCR assay (qPCR)}

Detection of C. burnetii DNA was performed with a TaqMan based qPCR assay targeting the repetitive element IS1111 as described by Klee et al. [35] using a Stratagene Mx3000P v 4.01Thermocycler (Agilent Technologies, Santa Clara, USA). No template control (NTC) and tenfold serial dilution of cloned IS1111 gene plasmid fragments ranging from $1 \times 10^{0}$ to $1 \times 10^{5}$ plasmid copy numbers were used for Coxiella DNA quantification and sensitivity control of the assay. Cycling conditions were as follows: one pretreatment cycle at $50{ }^{\circ} \mathrm{C}$ for $2 \mathrm{~min}$, initial denaturation at $95{ }^{\circ} \mathrm{C}$ for $10 \mathrm{~min}$, followed by 50 cycles at $95^{\circ} \mathrm{C}$ for denaturation for $15 \mathrm{~s}$, and $30 \mathrm{~s}$ for annealing and elongation at $60^{\circ} \mathrm{C}$. No internal amplification control (IAC) was used in the procedure to ensure high sensitivity. Cycle threshold $(\mathrm{Ct})$ values $\leq 36$ cycles were interpreted as positive. The threshold was calculated automatically by the instruments' software based on six 10 fold serial dilutions of C. burnetii DNA in negative human sera assessed simultaneously in a single run.

\section{Case definitions}

Acute Q fever case was defined as a patient with compatible clinical evidence criteria and laboratory supportive results for acute $\mathrm{Q}$ fever illness, reflected by elevated IgG phase I and phase II antibodies by ELISA and confirmed by C. burnetii phase II antibodies titers of $>1: 128$ by IFA assay or detection of Coxiella DNA by qPCR. Chronic case was defined as those with elevated IgG phase I antibodies by ELISA and phase I antibodies titers of $\geq 1: 800$ by IFA assay. The case definition criteria was based on a combination of recommendations of the kits manufacturer and as proposed by EFSA [2], CDC [7], and previous authors $[8,9,36]$. In all cases, Salmonella spp, Brucella spp, and Plasmodium spp were excluded. For statistical analysis, seropositivity was defined as any participant who met the criteria for acute or chronic Q fever.

\section{Data management and statistical analysis}

Questionnaire results and serological data were entered into Microsoft excel 2010 spreadsheet and exported to SPSS Statistics software ${ }^{\circ}$ (Armonk, IBM Corp, USA. v.20) and verified against the paper questionnaires and laboratory sheets for consistency and completeness. The Pearson's $X^{2}$ test or Fisher's exact test was used to determine differences in $\mathrm{Q}$ fever seroprevalence among demographic groups. Statistical significance was set at $P$ value $<0.05$.

Multivariate logistic regression models were built to assess clinical features, and plausible socio-demographic, economic and dietary characteristics of the patients associated with $\mathrm{Q}$ fever seropositivity using stepwise backward analysis procedure. Briefly, univariate analysis was performed for all covariates in each model and pair-wise collinearity assessed using Spearman rank correlation. A pair of the variables was considered collinear if the correlation coefficient was equal or greater than 0.8. Multi collinearity was then assessed for all potential variables by estimating the variance inflation factor (cut-off 5 ) and tolerance (cut-off 0.2 ) levels using collinearity diagnostics function (IBM Corp, USA. v.20). The variables were then droped or aggregated as appropriate.

The candidate covariates with $p<0.2$ using (Wald test) were fitted into the multivariable model and those exhibiting the highest p-values (Wald test) were removed one at a time from the model until all the retained variables had $p<0.05$. The eliminated variables were rescreened for confounding and were retained if their inclusion caused $20 \%$ or more change to the coefficients 
of one or more of the retained variables. Age was considered to be a biologically important variable and thus was kept in the final model. Finally, both the clinical and putative socio-economic and dietary characteristics from the two sub models were combined in a multivariate analysis to identify the independent risk determinants for Q fever seropositivity. The Hosmer-Lemeshow test was used for assessing final models' goodness of fit (GOF). The area under the ROC curve was also generated to assess the predictive ability of the final best model.

To derive and evaluate a predictive clinical model best-fit for identification of a subgroup of patients with high likelihood of acute $\mathrm{Q}$ fever, the patients were randomly assigned to derivation set and validation set using random number generated using the SPSS random number generator function (IBM Corp, USA. v.20). The derivation set used to fit the model composed of $65 \%$ of the sample $(n=707)$ while the validation set used to validate the model was made up of $35 \%$ of the sample ( $n=$ 360) [37]. A clinical prediction score " $Q$ fever score" was then generated using the $\beta$ coefficients of the final best fit model and the discriminatory power of this score evaluated by the area under the receiver operating characteristics (ROC) curve at the $95 \%$ confidence interval (CI). Then a cut-off value to estimate the diagnostic sensitivity and specificity in the validation set was selected [38].

\section{Results}

\section{Study population}

A total of 1067 participants (WDH: 536 and GPH: 531) were enrolled in the study. The study participants were fairly distributed between male and female (45.6 vs $54.4 \%)$. Nine hundred thirty-six participants were adults (>18 years), of which 963 (90.3\%) were of Somali ethnicity. Whereas most of the patients did not have any formal education $(n=661 ; 61.9 \%)$, nearly half $(n=448$; $42.0 \%)$ had knowledge about zoonosis but only 5 $(0.5 \%)$ reported prior knowledge of Q fever. Eight hundred eighty-five patients reported regular contact with at least one animal species. Out of these, the Somali ethnic group reported more contacts $(n=818 ; 84.9 \%)$ than other ethnic groups $(n=67 ; 64.4 \%)$. Demographic characteristics of patients as well as the number positive for acute $\mathrm{Q}$ fever are shown in Table 1.

Majority $(n=689 ; 64.6 \%)$ of the participants reported regular contact with goats whilst less than half had contact with cattle $(n=465 ; 43.6 \%)$ and sheep $(n=392$; $36.7 \%)$. Only 112 (10.5\%) reported regular exposure to camels. The type of exposure included; animal grazing ( $n=717 ; 67.2 \%)$, handling of raw milk ( $n=597 ; 56 \%)$, and animal slaughter $(n=382 ; 35.8 \%)$. One hundred fifty-eight $(14.8 \%)$ patients reported to help in animal parturition and 44 (4.1\%) reported exposure to aborted or after birth animal materials. Consumption of raw milk was common among the participants. Almost all participants of Somali origin $(n=907 ; 94.2 \%)$ reported consumption of raw milk. Less than a half $(n=38 ; 36.5 \%)$ of other ethnic groups reported to do so. Consumption of raw camel milk ( $n=943 ; 88.4 \%)$, raw cattle milk $(n=$ $331 ; 31 \%)$, and locally fermented milk product $(n=409$; $38.3 \%)$ were commonly reported, whereas consumption of raw goat milk was less common $(n=184 ; 17.2 \%)$. Table 2 summarizes the frequency of animal contacts and dietary exposure of the study participants and numbers positive for acute $\mathrm{Q}$ fever.

\section{Seroprevalence}

A total of 204 (19.1\%, $95 \%$ CI: 16.8-21.6) participants were found to be positive for $\mathrm{Q}$ fever based on a parallel interpretation of the three tests applied. Of these, 181 (17.0 \%, 95\%CI: 14.8-19.4) had anti-Coxiella phase II IgG antibodies while 175 (16.4 \%, 95\%CI: 14.2-18.8) had IgG antibodies against phase I antigens. One hundred ninetyfour (18.2 \%, $95 \%$ CI: 15.9-20.7 \%) patients were positive for IgG antibodies against either phase II or phase I antigens, whilst 162 (15.2\%, $95 \%$ CI: 13.2-17.5) patients were found to be positive for anti-Coxiella IgG antibodies against both phase I and phase II antigens (Table 1). Thirteen and eighteen participants tested positive for only IgG phase I and IgG phase II antigens, respectively. One patient remained positive for IgG phase II and borderline for phase I in the repeat tests. Based on the study case definition criteria, acute Q fever was established in a total of 163 (15.3\%, $95 \%$ CI: 13.2-17.6) patients whereas none of the patients had IgG antibody titers against phase I supportive of chronic $\mathrm{Q}$ fever infection.

\section{Molecular detection of $\mathrm{Q}$ fever}

Quantitative real-time PCR (qPCR) demonstrated $C$. burnetii specific DNA in $2.2 \%(10 / 448)$ of the examined patients, of which all were serologically negative for $\mathrm{Q}$ fever. The tested sera were from patients whose onset of the illness was $\leq 2$ weeks and had no antibiotic therapy. The PCR of whole blood or serum is mainly positive within the first two weeks following symptom onset, and becomes negative as the antibody response develops. Detectable seroconversion typically occurs one to three weeks after symptoms appear [39].

Q fever was not clinically suspected by the treating clinicians in any of 173 (16.2\%) positive patients, instead the working diagnosis were mainly presumptive typhoid fever (45.1\%), malaria (6.9\%), pneumonia oracute respiratory infections (37.6\%) and others or fever of unknown origin (FUO) $(10.4 \%)$. There was no significant difference in infection found between males and females $(P=0.736)$. Higher seroprevalence (16.7 \%, 95 \% CI: 14.4-19.3) was found 
Table 1 Demographic characteristics of study participants and numbers positive for acute Q fever among the febrile patients, Northeastern Kenya

\begin{tabular}{|c|c|c|c|c|c|c|c|c|}
\hline Variable & Total Number (\%) & IgG PII positive $(N=1067)$ & IgG PI positive $(N=1067)$ & IgG PI/PII positive $(N=1067)$ & qPCR positive $(N=448)$ & Q fever positive ${ }^{\text {a }}(\%)(N=1067)$ & $95 \%(\mathrm{Cl})$ & $P$-value \\
\hline \multicolumn{9}{|l|}{ Age Group (years) } \\
\hline $0-18$ & $131(12.3)$ & 16 & 15 & 18 & 0 & $17(13.0)$ & $8.0-20.2$ & 0.283 \\
\hline $18+$ & $936(87.7)$ & 165 & 160 & 176 & 10 & $156(16.7)$ & $14.4-19.3$ & \\
\hline Total & $1067(100 \%)$ & $181(17.0 \%)$ & $175(16.4 \%)$ & $194(18.2 \%)$ & $10(2.2 \%)$ & $173(16.2 \%)$ & $14.1-18.7$ & - \\
\hline \multicolumn{9}{|l|}{ Gender } \\
\hline Female & $580(54.4)$ & 102 & 98 & 109 & 4 & $96(16.6)$ & $13.7-22.9$ & 0.736 \\
\hline Male & $487(45.6)$ & 79 & 77 & 85 & 6 & $77(15.8)$ & $12.6-19.4$ & \\
\hline \multicolumn{9}{|l|}{ Occupation } \\
\hline Herder & $678(63.5)$ & 140 & 138 & 150 & 7 & $134(19.8)$ & $16.9-23.1$ & $<0.001$ \\
\hline Civil servant & $142(13.3)$ & 10 & 8 & 10 & 0 & $9(6.3)$ & $3.1-12.2$ & \\
\hline General merchandise & $74(6.9)$ & 8 & 7 & 9 & 0 & $6(8.1)$ & $3.3-17.4$ & \\
\hline Livestock trader & $59(5.5)$ & 15 & 14 & 16 & 2 & $15(25.4)$ & $15.4-38.7$ & \\
\hline Student & $62(5.8)$ & 4 & 5 & 5 & 0 & $5(8.1)$ & $3.0-18.5$ & \\
\hline Others & $52(4.9)$ & 4 & 3 & 4 & 1 & $4(7.7)$ & $2.5-19.4$ & \\
\hline \multicolumn{9}{|l|}{ Education Level } \\
\hline None & $661(61.9)$ & 129 & 132 & 141 & 7 & $130(19.7)$ & $16.8-22.9$ & $<0.001$ \\
\hline Post-secondary & $114(10.7)$ & 12 & 10 & 12 & 0 & $10(8.8)$ & $4.5-15.9$ & \\
\hline Primary & $206(19.3)$ & 36 & 29 & 37 & 2 & $30(14.6)$ & $10.2-20.3$ & \\
\hline Secondary & $86(8.1)$ & 4 & 4 & 4 & 1 & $3(3.5)$ & $1.1-9.8$ & \\
\hline \multicolumn{9}{|l|}{ Residence county } \\
\hline Garissa & $531(49.7)$ & 86 & 84 & 93 & 6 & $83(15.6)$ & $12.7-19.1$ & 0.607 \\
\hline Wajir & $536(50.3)$ & 95 & 91 & 101 & 4 & $90(16.8)$ & $13.8-20.3$ & \\
\hline \multicolumn{9}{|l|}{ Ethnic groups } \\
\hline Somali & $963(90.3)$ & 173 & 167 & 188 & 8 & $165(17.1)$ & $14.8-19.7$ & 0.004 \\
\hline Others & $104(9.7)$ & 8 & 8 & 6 & 2 & $8(7.7)$ & $3.6-15.4$ & \\
\hline \multicolumn{9}{|l|}{ Zoonosis knowledge } \\
\hline Yes & $448(42.0)$ & 62 & 61 & 67 & 2 & $58(12.9)$ & $10.0-16.5$ & \\
\hline No & $619(58.0)$ & 119 & 114 & 127 & 8 & 115 (18.6) & $15.6-21.9$ & 0.012 \\
\hline \multicolumn{9}{|l|}{ Q Fever knowledge } \\
\hline Yes & $5(0.5)$ & 0 & 0 & 0 & 0 & 0 & - & \\
\hline No & 1062 (99.5) & 181 & 175 & 194 & 10 & $173(16.2)$ & $14.1-18.7$ & \\
\hline
\end{tabular}

Cl confidence interval, IgG PII/I lgG antibodies against phase II/I Coxiella antigens

a Patients meeting case definition for acute $\mathrm{Q}$ fever by serology or Coxiella DNA detection by GPCR 
Table 2 Frequency of animal contacts and dietary exposure self-reported by febrile patients in Northeastern Kenya

\begin{tabular}{|c|c|c|c|c|c|}
\hline Characteristic & Variable & Total No. patients (\%) & Positive for Q fever ${ }^{\mathrm{a}}(\%)$ & Crude OR $(95 \% \mathrm{Cl})$ & $P$ value \\
\hline \multirow[t]{2}{*}{ Contact with goat } & No & 378 & $52(13.70)$ & Ref & - \\
\hline & Yes & 689 & $121(17.6)$ & $4.82(2.89-8.26)$ & 0.003 \\
\hline \multirow[t]{2}{*}{ Contact with dog } & Yes & 22 & $1(4.5)$ & Ref & - \\
\hline & No & 1045 & $172(16.5)$ & $0.24(0.03-1.81)$ & 0.267 \\
\hline \multirow[t]{2}{*}{ Contact with sheep } & No & 675 & $104(15.4)$ & Ref & - \\
\hline & Yes & 392 & $69(17.6)$ & $1.17(0.84-1.64)$ & 0.349 \\
\hline \multirow[t]{2}{*}{ Contact with cattle } & No & 602 & $63(10.5)$ & Ref & - \\
\hline & Yes & 465 & $110(23.7)$ & $2.65(1.89-3.72)$ & $<0.001$ \\
\hline \multirow[t]{2}{*}{ Contact with camel } & Yes & 112 & $13(11.8)$ & Ref & - \\
\hline & No & 955 & $160(16.7)$ & $0.67(0.37-1.22)$ & 0.279 \\
\hline \multirow[t]{2}{*}{ Frequent slaughtering of animals } & No & 685 & $68(9.90)$ & Ref & - \\
\hline & Yes & 382 & $105(27.5)$ & $3.44(2.46-6.67)$ & $<0.001$ \\
\hline \multirow[t]{2}{*}{ Frequent handling of raw milk } & No & 470 & $61(13.0)$ & Ref & - \\
\hline & Yes & 597 & $112(18.8)$ & $1.55(1.10-2.18)$ & 0.011 \\
\hline \multirow[t]{2}{*}{ Contact with birth products ${ }^{b}$} & No & 865 & $148(17.1)$ & Ref & - \\
\hline & Yes & 202 & $25(12.4)$ & $1.43(0.94-2.19)$ & 0.089 \\
\hline \multirow[t]{2}{*}{ Share house with animals } & Yes & 98 & $20(20.4)$ & Ref & - \\
\hline & No & 969 & $153(15.8)$ & $0.37(0.08-1.31)$ & 0.239 \\
\hline \multirow[t]{2}{*}{ Frequent contact with wildlife } & Yes & 2 & $0(0)$ & - & - \\
\hline & No & 1065 & $173(16.2)$ & & \\
\hline \multirow[t]{2}{*}{ Frequently prepare manure } & Yes & 50 & $11(22.0)$ & Ref & - \\
\hline & No & 1017 & $162(15.9)$ & $1.49(0.44-1.97)$ & 0.258 \\
\hline \multirow[t]{2}{*}{ Frequently graze animals } & No & 350 & $37(10.6)$ & Ref & - \\
\hline & Yes & 717 & $136(19.0)$ & $1.98(1.34-2.92)$ & $<0.001$ \\
\hline \multirow[t]{2}{*}{ Frequent consumption of raw meat } & Yes & 57 & $14(24.6)$ & Ref & - \\
\hline & No & 1010 & $159(15.7)$ & $0.74(0.13-3.26)$ & 0.382 \\
\hline \multirow[t]{2}{*}{ Frequent consumption of raw cattle milk } & No & 736 & $57(7.7)$ & Ref & - \\
\hline & Yes & 331 & $116(35.0)$ & $6.43(4.52-9.14)$ & $<0.001$ \\
\hline \multirow[t]{2}{*}{ Frequent consumption of raw goat milk } & No & 883 & $130(14.7)$ & Ref & - \\
\hline & Yes & 184 & $43(23.4)$ & $1.77(1.20-2.61)$ & 0.004 \\
\hline \multirow[t]{2}{*}{ Frequent consumption of raw camel milk } & No & 124 & $17(13.7)$ & Ref & - \\
\hline & Yes & 943 & $156(16.5)$ & $1.24(0.73-2.14)$ & 0.422 \\
\hline \multirow[t]{2}{*}{ Frequent consumption of locally fermented milk } & No & 658 & $60(9.1)$ & Ref & - \\
\hline & Yes & 409 & $113(27.6)$ & $3.81(2.7-5.36)$ & $<0.001$ \\
\hline \multirow[t]{2}{*}{ Frequent consumption of animal blood } & Yes & 45 & $3(6.7)$ & Ref & - \\
\hline & No & 1022 & $170(16.6)$ & $0.36(0.11-1.17)$ & 0.809 \\
\hline
\end{tabular}

Ref referent category, $\mathrm{OR}$ odd ratio, $\mathrm{Cl}$ confidence interval

aPatients meeting case definition for acute Q fever by serology or Coxiella DNA detection by qPCR

${ }^{\mathrm{b}}$ Proportion of patients with recent exposure to aborted materials or help during animal birth

Bold font implies statistically significant results at $(P<0.20)$ that were retained as possible factors and subsequently fitted in the multivariate analysis

in adults ( $>18$ years) when compared to those aged below (13.0\%, $95 \%$ CI: 8.0-20.2), but the difference was not statistically significant $(P=0.283)$. Somalis were more often seropositive when compared with other ethnic groups (Somali, $17.1 \%$, 95\%CI: 14.8-19.7 and Non-
Somali, 7.7 \%, 95\%CI: 3.6-15.4, $P=0.004$, Table 1). Among 885 participants who reported regular contact with animals, 160 (18.1 \%, 95\%CI: 15.7-20.8) tested positive for Q fever whereas only 13 (7.1\%, $95 \%$ : CI: 4.10-12.2) who reported no contact with animals were 
positive $(P<0.001)$. Most cases of $\mathrm{Q}$ fever occurred in full time herders 134 (19.8\%,95\%CI: 16.9-23.1) and livestock trader 15 (25.4\%, 95\%CI: 15.4-38.7) when compared to government workers, general merchandise businesses and other occupations $(P<0.001)$. Patients from Wajir county were slightly more seropositive 90 (16.8 \%, 95\%CI: 13.8-20.3) than those from Garissa county 83 (15.6\%, $95 \%$ : CI: $12.7-19.1)$ but the difference was not statistically significant $(P=0.607)$. Finally, patients without knowledge of zoonosis 115 (18.6\%, 95\%CI: $15.6-21.9, P=0.012)$ and those without any form of education $130(19.7 \%, 16.8-22.9, P<0.001)$ were more often seropositive (Table 1).

\section{Clinical predictors of acute $Q$ fever diagnosis and ' $Q$ fever' score}

There were 392 (55.4\%) females in the 707 derivation cohort and 188 (52.2 \%) females in the 360 validation group. The mean age was 33.6 years (Standard Deviation [SD], 12.2 years) for derivation group and 38.3 years (SD 17.7 years) for the validation group. The mean interval from the onset of fever symptoms until hospital presentation was 14.5 days (SD 10.6 days)/median 8 days for cases in the derivation cohort and 11.9 days (13.2 days)/median
7 days for the validation group. The symptoms and clinical features of the patients are summarized in Table 3. Although the symptoms reported from patients were often combined, Table 3 presents the number of cases in which a particular symptom was reported. Acute Q fever was established in $116(16.4 \%)$ patients in the derivation group while 57 (15.8\%) patients tested positive in the validation group. Differential diagnosis for selected febrile etiologies was undertaken among the patients, including those classified as with FUO. The tests were selected based on the patients' clinical syndrome, the most prevalent infections reported to occur in the region and the nature of available laboratory support. These included screening the patients for typhoid fever, malaria, and brucellosis (data not included here). Supportive radiological investigations, hematology and liver enzyme tests were scarcely available and are not presented here.

Univariate analysis of the signs and symptoms revealed that general body malaise and fatigue, ALRI, constipation, abdominal pain, diarrhoea, and fever onset ( $>2$ weeks) were possibly associated with $\mathrm{Q}$ fever seropositivity $(P<0.20$; Table 3).

In the final clinical logit model, adjusted for possible confounding variables, ALRI (adjusted Odds ration [aOR]:

Table 3 Symptoms and clinical features of the febrile patients, Northeastern Kenya

\begin{tabular}{|c|c|c|c|c|}
\hline Variable & Total No. $(n=707)$ & Positive for $\mathrm{Q}$ fever $^{\mathrm{a}}(\%)(n=116)$ & Crude OR (95\%Cl) & P-value \\
\hline Headache & 630 & $104(16.5)$ & $1.07(0.56-2.05)$ & 0.836 \\
\hline Chills & 388 & $64(16.5)$ & $1.04(0.68-1.51)$ & 0.945 \\
\hline Arthralgia/Myalgia & 541 & $87(16.1)$ & $0.91(0.57-1.44)$ & 0.673 \\
\hline Malaise/Fatigue & 493 & $87(17.6)$ & $1.37(0.87-2.15)$ & 0.178 \\
\hline Anorexia & 404 & $62(15.3)$ & $0.84(0.56-1.25)$ & 0.380 \\
\hline ALRI & 200 & $61(30.5)$ & $3.61(2.39-5.44)$ & $<0.001$ \\
\hline Constipation & 129 & $28(21.7)$ & $1.54(0.96-2.48)$ & 0.074 \\
\hline Night Sweats & 94 & $12(12.8)$ & $0.71(0.38-1.36)$ & 0.308 \\
\hline Diarrhoea & 73 & $8(11.0)$ & $0.60(0.28-1.29)$ & 0.081 \\
\hline Weight loss & 62 & $11(17.7)$ & $1.11(0.56-2.20)$ & 0.765 \\
\hline Confusion & 15 & $1(6.6 \%)$ & $0.31(0.01-7.09)$ & 0.801 \\
\hline Rash & 28 & $6(21.4)$ & $1.41(0.56-3.56)$ & 0.466 \\
\hline Vomiting & 13 & $1(7.7)$ & $0.42(0.05-3.23)$ & 0.401 \\
\hline Abdominal pain & 173 & $37(21.4)$ & $1.57(1.01-2.42)$ & 0.043 \\
\hline Palpable spleen & 91 & $18(19.8)$ & $1.31(0.56-8.69)$ & 0.640 \\
\hline Palpable liver & 38 & $5(13.1)$ & $0.78(0.34-1.47)$ & 0.486 \\
\hline Fever onset (>14 days) & 253 & $108(42.7)$ & $41.52(19.78-87.22)$ & $<0.001$ \\
\hline Age (>18 years) & 618 & $106(17.2)$ & $1.64(0.82-3.26)$ & 0.162 \\
\hline \multicolumn{5}{|l|}{ Mean (SD) } \\
\hline Age (years) & 707 & $33.6 \pm 12.2$ & & \\
\hline Fever onset (days) & 707 & $14.5 \pm 10.6$ & & \\
\hline
\end{tabular}

$A L R I$ acute lower respiratory infection, $O R$ odds ratio, $C I 95 \%$ confidence interval, SD standard deviation

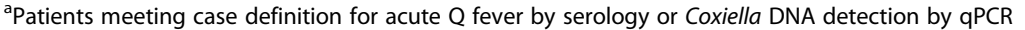

Bolded variables were considered significant $(P<0.20)$ and fitted into multivariate logistic regression model 
2.68, 95\%CI: 1.65-4.36), fever onset (>2 weeks) (aOR: 37.59, 95\%CI: 17.83-79.27) and abdominal pain (aOR 2.19, 95\%CI: 1.02-4.72) were positive predictors of Q fever infection. The analysis revealed that diarrhoea (aOR: 0.34, 95\%CI: 0.12-0.96) had predictive value for a negative acute $\mathrm{Q}$ fever outcome $(P<0.05$; Table 4$)$. Using the four variables, predictive score was generated and the scale simplified by assigning values to the nearest one decimal scale (fever onset $>2$ weeks: +3.6 , ALRI: +1.0 , abdominal pain: + 0.8 and diarrhoea: -1.1 , Table 4 ). The discriminatory power of the fitted ROC curve area was 0.883 (95\%CI: $0.851-$ 0.915, $P<0.001$, Fig. 2a). An optimal cut-off value of 2.90 (sensitivity $93.1 \%$ and specificity $76.1 \%$ ) was selected (Fig. 2b). Only a history of fever ( $>14$ days) singly was a good predictor of positive diagnosis (sensitivity $90.5 \%$ and specificity $76.8 \%$ ). The prediction remained strong, if diarrhoea was absent or when at least one of positive predictors was also present. However, none of other clinical predictors (ALRI or abdominal pains) alone or in combination had significant predictive value for positive acute $Q$ fever outcome. Thus, pre-admission fever onset ( $>14$ days) in association with ALRI and abdominal pain and no diarrhoea was the best predictor algorithm for acute $\mathrm{Q}$ fever outcome.

Table 4 Result of multivariate analysis showing significant clinical predictors for acute $\mathrm{Q}$ fever and calculation of $\mathrm{Q}$ fever score

\begin{tabular}{lllll}
\hline Variable & $\begin{array}{l}\text { Crude OR } \\
(95 \% \mathrm{Cl})\end{array}$ & aOR (95\%Cl) & $\beta$ & $\begin{array}{l}\text { P- } \\
\text { Coefficient }\end{array}$ \\
value
\end{tabular}

$A L R I$ acute lower respiratory infection, Ref referent category, aOR adjusted odds ratio, $\mathrm{Cl} 95 \%$ confidence interval, $\mathrm{H}$ - $\mathrm{L}$ test Hosmer-Lemeshow goodnessof-fit test, $R O C$ receiver operating characteristics, $A \cup C$ area under the curve
The prediction rule, reliably identified febrile patients with a score $>2.90$ as 12.7 times more likely to have a positive acute $\mathrm{Q}$ fever test outcome $(\mathrm{OR}=12.7$; 95 \% CI: 4.8932.72) than the patients with a $\mathrm{Q}$ fever score up to 2.90 .

\section{Risk factor analysis for acute $\mathbf{Q}$ fever}

Univariate analyses of demographic, social-economic and dietary characteristics showed no significant associations with seropositivity between gender, county of residence of the patient or across different age strata, and occupations except herders (OR; 2.96, 95 \% CI: 1.15-8.34) and livestock traders (OR; 4.09, 95 \% CI: 1.26-13.27) who had significantly higher odds for seropositivity. Having secondary education or above (OR; 0.39, $95 \%$ CI: 0.17-0.81) and knowledge about zoonosis (OR; $0.78 \mathrm{CI}$ : 0.36-0.99) were associated with decreased risk of $\mathrm{Q}$ fever seropositivity. Odds of Q fever seropositivity were significantly higher for patients of Somali ethnicity (OR; 1.92, 95 \% CI: 1.29-3.76).

Regular contact with cattle (OR; 2.65, 95 \% CI: 1.893.72) or goats (OR; 4.82, 95 \% CI: 2.89-8.26) were independently associated with $\mathrm{Q}$ fever seropositivity. The risk for Coxiella infection was higher for those who reported the following: contact with aborted materials or assist in animal births (OR; 1.43, 95 \% CI: 0.94-2.19), handling raw milk (OR; 1.55, 95 \% CI: 1.10-2.18), grazing animals (OR; 1.98, $95 \%$ CI: 1.34-2.92), and slaughtering of animals (OR; 3.44, 95 \% CI: 2.46-6.67). Q fever seropositivity was significantly associated with consumption of raw cattle milk (OR; 6.43, 95 \% CI: 4.52-9.14), raw goat milk (OR; 1.77, 95 \% CI: 1.20-2.61) and locally fermented milk products (susac) (OR; 3.81, 95 \% CI: 2.73-5.36) (Table 2).

In the final combined multivariate analyses, significant association persisted for pre-admission fever ( $>14$ days) (aOR; 36.35, 95 \% CI: 19.84-69.49) and ALRI (aOR; 2.41, 95 \% CI: 1.53-6.36), while abdominal pain (aOR; 1.95, 95 \% CI: 1.28-3.58) association with seroposivity was strengthened.

Regular contact with cattle (aOR: 2.09, 95 \% CI: $1.73-$ 5.98 ), or goats (aOR: 3.74, $95 \%$ CI: 2.52-9.40) and frequent slaughter of animals (aOR: 1.78, 95 \% CI: 1.092.91) remained with significantly higher odds of seropositivity. The dietary exposures significantly associated with seropositivity in the final combined model included: consumption of raw cattle milk (aOR: 2.49, 95\%CI: 1.48-4.21) and locally fermented milk products (aOR: 1.66, 95\%CI: 1.19-4.37).

The odds of $\mathrm{Q}$ fever were lower for patients who presented with diarrhoea (aOR; 0.63, 95 \% CI: 0.38-1.00) and for those with secondary education or above at the time of hospital visit (aOR; 0.71, 95 \% CI: 0.24-0.96) (Table 5).

\section{Discussion}

This cross-sectional study from a pastoralist community in Kenya found an unexpectedly high prevalence (16.2 \%) 


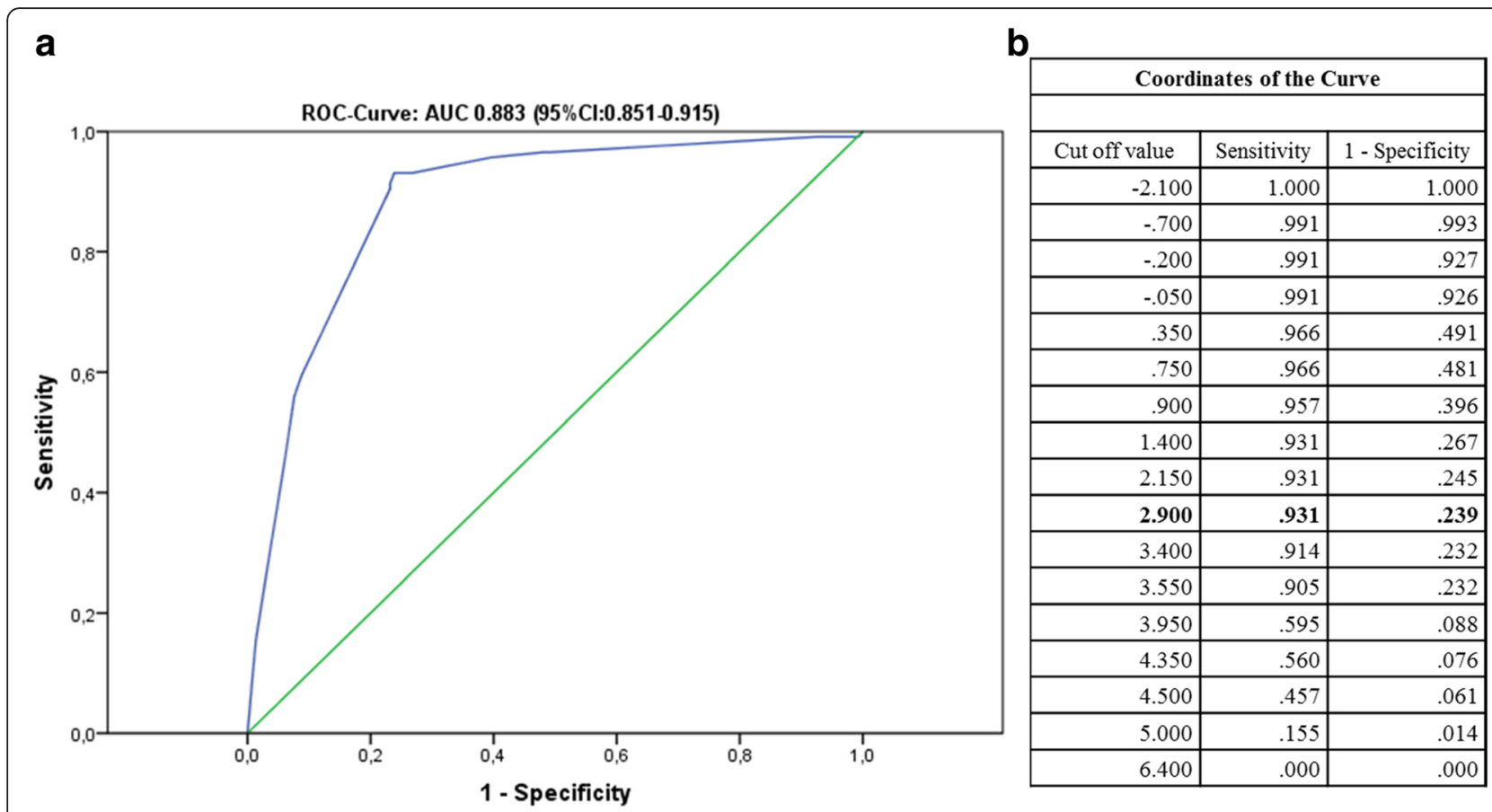

Fig. 2 a Receiver Operating Characteristics (ROC) and Area Under the Curve (AUC) for assessing the discriminatory capacity of the Q fever score. b Cut-off values for the ROC curve

of acute $\mathrm{Q}$ fever in febrile patients who were not suspected of $Q$ fever infection during hospital diagnosis. Instead these patients were mainly suspected for the common tropical fevers or fever of unknown origin. Previous studies in Kenya have found that a considerable proportion of febrile patients still continue to be treated for presumptive malaria and blood stream infections using antimalarials and penicillin based antibiotics, respectively [40-42]. However, these treatments have no activity against $C$. burnetii. Though not directly assessed in the present study, our findings strongly suggest that patients with $\mathrm{Q}$ fever were likely to leave hospital without the specific treatment for $\mathrm{Q}$ fever. These results taken together with previous studies elsewhere in Africa [27, 40, 41, 43, 44], provide further evidence that in absence of clear guidelines for the management of febrile illness and incorporation of reliable diagnostic tests in the hospitals to enable accurate fever diagnosis, clinicians continues to encounter missed opportunities to accurately detect and treat other causes of fever. The patients thus don't benefit from appropriate antibiotic therapy.

The prevalence of $\mathrm{Q}$ fever in this study compare to that reported in similar studies in Burkina Faso (13.1\%) [45] and Egypt (12\%) [46], but the seroprevalence was considerably higher than that reported in Tunisia (8\%) [27], Mali (5 \%) [26] and Tanzania (5\%) [43]. Similarly, our results do not correspond to the findings of studies conducted in Croatia (27.5 \%) [47], Iran (35.2 \%) [48] and Turkey (36 \%) [49], respectively. However, it is difficult to compare findings of studies done in different countries because of the different sampling criteria, selected study population, and the different laboratory tests and cut-offs used that may affect the outcomes.

We found no significant difference in infection among individual age groups or sex. This is dissimilar to previous studies in different (high-income) settings [1, 50, 36] which suggest that older persons (25-60 years) and men are at a greater risk of infection due to cumulative risk of exposure and men dominance in risky occupations. In contrast, a study by Muga et al. [15] described nomadic pastoralism in Kenya as highly labor-intensive and work is shared out almost entirely by all household members (including children above four years). This implies that the entire population may be at risk of exposure to infected animals or materials very early in life.

In our study, a new prediction score ( $Q$ fever score) reliably differentiated acute $\mathrm{Q}$ fever infection in febrile patients with undifferentiated illness. With a cut off value of 2.90 (sensitivity $93.1 \%$ and specificity $76.1 \%$ ), the best diagnostic algorithm; history of fever ( $>14$ days) singly without diarrhoea, or in associated with ALRI and/or abdominal pains had the best predictive value for positive acute Q fever outcome. On the contrary, ALRI or abdominal pains present alone or in combination did not meet the threshold predictive of infection and especially when associated with diarrhoea. To our knowledge, this is the 
Table 5 Results of final combined logistic regression analysis showing risk factors found associated with Q fever seropositivity in febrile patients, northeastern Kenya

\begin{tabular}{|c|c|c|c|c|c|}
\hline Risk factor & Variable & Crude OR & P-value & $\mathrm{aOR}(95 \% \mathrm{Cl})$ & $P$-value \\
\hline \multirow[t]{5}{*}{ Age Groups (years) } & $<19$ & Ref & - & Ref & - \\
\hline & $>19-29$ & $0.70(0.37-1.35)$ & 0.282 & $1.16(0.63-3.92)$ & 0.178 \\
\hline & $30-39$ & $1.52(0.86-2.65)$ & 0.145 & $1.86(0.55-8.26)$ & 0.433 \\
\hline & $40-49$ & $1.73(0.97-3.10)$ & 0.063 & $2.03(0.87-4.38)$ & 0.609 \\
\hline & $>50$ & $1.28(0.66-2.48)$ & 0.458 & $1.21(0.51-2.97)$ & 0.124 \\
\hline \multirow[t]{2}{*}{ Gender } & Female & Ref & - & - & - \\
\hline & Male & $0.95(0.68-1.31)$ & 0.736 & & \\
\hline \multirow[t]{2}{*}{ Residence county } & Garissa & Ref & - & - & \\
\hline & Wajir & $1.09(0.78-1.51)$ & 0.607 & & \\
\hline \multirow[t]{2}{*}{ Higher education } & Yes & Ref & - & Ref & - \\
\hline & No & $0.39(0.17-0.81)$ & $<0.001$ & $0.71(0.24-0.96)$ & 0.038 \\
\hline \multirow[t]{2}{*}{ Ethnicity } & Other & Ref & - & - & - \\
\hline & Somali & $1.92(1.29-3.76)$ & 0.004 & & \\
\hline \multirow[t]{2}{*}{ Zoonosis knowledge } & No & Ref & & - & - \\
\hline & Yes & $0.78(0.36-0.99)$ & 0.025 & & \\
\hline \multirow[t]{6}{*}{ Occupation } & Others & Ref & - & - & - \\
\hline & Livestock trader & $4.09(1.26-13.27)$ & 0.019 & & \\
\hline & Student & $1.05(0.26-4.14)$ & 0.941 & & \\
\hline & General merchandise & $1.06(0.28-3.96)$ & 0.932 & & \\
\hline & Civil servant & $0.81(0.39-2.76)$ & 0.739 & & \\
\hline & Herder & $2.96(1.15-8.34)$ & 0.041 & & \\
\hline \multirow[t]{15}{*}{ Animal Contact } & Cattle & & & & \\
\hline & No & Ref & - & Ref & - \\
\hline & Yes & $2.65(1.89-3.72)$ & $<0.001$ & $2.09(1.73-5.98)$ & 0.004 \\
\hline & Goats & & & & \\
\hline & No & Ref & - & Ref & - \\
\hline & Yes & $4.82(2.89-8.26)$ & 0.003 & $3.74(2.52-9.40)$ & 0.006 \\
\hline & Frequent slaughter of animals & & & & \\
\hline & No & Ref & - & Ref & - \\
\hline & Yes & $3.44(2.46-6.67)$ & $<0.001$ & $1.78(1.09-2.91)$ & 0.021 \\
\hline & Contact with birth products ${ }^{\mathrm{a}}$ & Ref & - & - & - \\
\hline & & $1.43(0.94-2.19)$ & 0.089 & & \\
\hline & Frequent handling of raw milk & Ref & - & - & - \\
\hline & & $1.55(1.10-2.18)$ & 0.011 & & \\
\hline & Frequently graze animals & Ref & - & - & - \\
\hline & & $1.98(1.34-2.92)$ & 0.030 & & \\
\hline \multirow[t]{7}{*}{ Dietary contact } & Frequent consumption of raw cattle milk & & & & \\
\hline & No & Ref & - & Ref & - \\
\hline & Yes & $6.43(4.52-9.14)$ & $<0.001$ & $2.49(1.48-4.21)$ & 0.001 \\
\hline & Frequent consumption of locally fermented products & & & & \\
\hline & No & Ref & - & Ref & - \\
\hline & Yes & $3.81(2.73-5.36)$ & $<0.001$ & $1.66(1.19-4.37)$ & 0.014 \\
\hline & Frequent consumption of raw goat milk & & & & \\
\hline
\end{tabular}


Table 5 Results of final combined logistic regression analysis showing risk factors found associated with Q fever seropositivity in febrile patients, northeastern Kenya (Continued)

\begin{tabular}{|c|c|c|c|c|c|}
\hline & No & Ref & - & - & - \\
\hline & Yes & $1.77(1.20-2.61)$ & 0.004 & & \\
\hline & ALRI & & & & \\
\hline & No & Ref & - & Ref & - \\
\hline & Yes & $3.61(2.39-5.44)$ & $<0.001$ & $2.41(1.53-6.36)$ & $<0.001$ \\
\hline \multirow[t]{9}{*}{ Clinical } & Abdominal pain & & & & \\
\hline & No & Ref & - & Ref & - \\
\hline & Yes & $1.57(1.01-2.42)$ & 0.004 & $1.95(1.08-3.58)$ & 0.019 \\
\hline & Diarrhoea & & & & \\
\hline & No & Ref & - & Ref & - \\
\hline & Yes & $0.60(0.28-1.29)$ & 0.042 & $0.63(0.38-1.00)$ & 0.047 \\
\hline & Fever onset (>14 days) & & & & \\
\hline & No & Ref & $-<0.001$ & Ref & - \\
\hline & Yes & $41.52(19.78-87.22)$ & & 36.35 (19.84-69.49) & $<0.001$ \\
\hline $\mathrm{H}$-L test & & & & & 0.412 \\
\hline ROC (AUC) & & & & $0.718(0.673-0.784)$ & $<0.001$ \\
\hline
\end{tabular}

Ref referent category, $a O R$ adjusted odds ratio, $\mathrm{Cl}$ confidence interval, $\mathrm{H}$ - $\mathrm{L}$ test Hosmer-Lemeshow goodness- of-fit test, $R O C$ receiver operating characteristics, $A U C$ area under the curve

${ }^{\text {aP }}$ proportion of patients with recent exposure to aborted materials or helped during animal birth

first study to evaluate such prediction rule for the diagnosis of acute $\mathrm{Q}$ fever. Whereas, previous studies designed to assess clinical and laboratory features of $\mathrm{Q}$ fever patients reported hepatitis and pneumonia as common clinical presentations, the authors did not propose a clinical prediction rule that could be of value during initial patient diagnosis [51, 52]. Other studies have assessed the sensitivity and specificity of individual signs and symptoms to establish clinical diagnosis of febrile etiologies such as typhoid fever [53], malaria [54, 55] and brucellosis relapse [56] in developing countries. Similar to our study, none of the constitutional symptoms proved a good predictor of infection. In our study, the new Q fever score demonstrated that patients with a score above the cut-off value of 2.90, were 12 times more likely to test positive for acute $\mathrm{Q}$ fever than those with a score upto the cutoff $(\mathrm{OR}=$ 12.7; 95 \% CI: 4.89-32.72, $P<0.001)$.

Within the past decade, malaria has substantially declined in many endemic countries [57]. This together with the increasing availability and use of malaria rapid diagnostic tests to exclude malaria have led substantial adherence to the WHO recommended "test and treat" policy. However, a growing body of evidence in Africa shows that clinicians are presently faced with a growing proportion of patients with severe febrile illness from previously under-recognized zoonotic diseases but tools to guide subsequent detection and management are often lacking [16, 17, 24-27, 40, 43]. Under these circumstances, the present new $\mathrm{Q}$ fever score would be of particular value to practicing clinicians working in resource limited countries in making decisions on patients necessitating meticulous attention in regard to $\mathrm{Q}$ fever during initial diagnosis and empiric treatment. For instance, using the score supported by screening patients for the risky epidemiological factors would be useful to clinicians to make clinical decisions on when to prefer prescribing doxycycline versus the commonly used penicillin based drugs during empiric treatment of fever of unknown origin in such underdeveloped areas. However, we acknowledge that this score may not provide a definitive clinical algorithm for acute Q fever detection because of the limitations of the present study, but a clinically supportive guide for clinicians.

We report for the first time the correlates of socioeconomic and dietary practices with $\mathrm{Q}$ fever seropositivity in Kenya. We found higher odds of seropositivity in individuals who reported regular occupational or domestic contact with goats, cattle and those involved in regular slaughter of animals, thus highlighting the significant role of livestock contact in transmission of C. burnetii. Slaughtering of animals (usually uninspected by health officials) is a common cultural practice of communities in the study area e.g. during Eid-al-Adha, dowry payment, and wedding ceremonies or during the regular diet preparation $[15,58]$. During these events, individuals may be exposed to a high risk of contracting $Q$ fever. Our results correspond well with previous studies in different countries that found higher seroprevalences in persons who were in close contact with cattle and goats. In addition, consumption of raw cattle milk (aOR: 
2.49) and the locally fermented milk products i.e. susac (aOR: 1.66) were important risk factors. This practice is also common among the pastoralist communities in the study area because of strong rooted cultural norms that associate unboiled milk with high nutrition value [31]. Indeed, most of the patients of Somali ethnic group were unaware that drinking raw camel or cattle milk was capable of causing diseases and thought that boiling was not necessary. These practices may present significant risk of exposure to milk borne pathogens as milk from different animals is pooled before consumption or fermented into the traditional products (susac) without a pre-heating step. Previous epidemiological studies have also described strong associations between consumption of raw milk and C. burnetii seropositivity [52, 59], but the risk of oral transmission is still widely considered as minimal compared to aerosol route [60, 61]. Therefore, this evidence can be strengthened by more research to definitively demonstrate the probability of infection through oral route and determination of pathogens dose capable of causing the disease.

\section{Limitations}

A potential limitation in our findings is that our study was hospital based where the population under investigation was febrile patients seeking treatment. Therefore, the afebrile cases or those that were unable to present to the hospitals were inevitably not captured by our sampling strategy. Again, the patient samples were generated in absence of a robust probabilistic sampling method. This has the effect of limiting the generalization of the results. A population-based survey or follow up of patients to obtain a convalescent sera sample was not feasible due to the nomadic lifestyle of the patients, the ongoing inter-clans conflicts and militia activities in the region. However previous studies have reported adequate performance of the used commercial serion ELISA classic test kits in detection of phase II specific IgG and IgM $[36,62]$ respectively, in diagnosis of acute $\mathrm{Q}$ fever. The novelty of the present study was that the ELISA positive sera were further confirmed with the reference diagnostic method (IFA) and the patients whose fever onset was $\leq 2$ weeks were further screened for $\mathrm{Q}$ fever using a quantitative real-time PCR. Nevertheless, the possibility of recent infection cases, false positive or chronic cases being considered as acute Q fever cannot be completely rule out.

The utility of our prediction score should be interpreted in the context of potential limitation. The cross-sectional nature of the study did not allow more comprehensive evaluation and follow up of each patient and the fact that the prediction rule was derived by logistic regression modeling which can be prone to residual confounding effects. Another potential limitation is related to the heterogeneous clinical presentation of $\mathrm{Q}$ fever in patients and the fact that the score was validated in patients from the same region where it was developed. Though deliberate efforts were made to exclude the commonly reported febrile etiologies in the region including typhoid fever, malaria and brucellosis, unfortunately due to the nature of the present study and scarcity of appropriate laboratory and radiological support, a comprehensive differential diagnosis for other febrile etiologies among our patients was not feasible. These factors may have affected the discriminatory index of the present score. Nevertheless, our study was not designed to give a definite clinical algorithm but one to help clinicians in distinguishing febrile cases probably due to $Q$ fever from febrile episodes not due to $Q$ fever and aid in making clinical empiric therapeutic decisions. Therefore, validation of the present prediction score in well-designed studies in diverse independent cohorts is highly warranted.

\section{General recommendations}

A one health approach for surveillance of emerging and remerging infectious diseases should be encouraged in Kenya to support design and implementation of rational control strategies for febrile diseases. Education programmes and appropriate preventive interventions targeting the significant risk factors needs to be designed for the communities at high risk of exposure. Increased clinician and laboratory personnel awareness and access to laboratory testing capacity is needed to enable timely detection and early treatment to prevent severe sequelae.

\section{Conclusions}

This is the first epidemiological study to report Q fever as a serious public health problem in Northeastern Kenya and a description of social-cultural, occupational, and dietary factors influencing human exposure. We present a simple predictive score based on clinical features. A Q fever score supported by screening patients for the risky epidemiological factors will ultimately help clinicians in making clinical judgments in distinguishing febrile illness probably due to $\mathrm{Q}$ fever from other etiologies and selection of appropriate therapeutic decisions (e.g. penicillin based antibiotics versus doxycycline for empiric treatment), particularly when no microbiological testing is available. The findings also provide a framework to initiate well-designed research in linked animal and human populations in different ethnic entities, agricultural production and management systems in Kenya.

\footnotetext{
Abbreviations

AFI, acute febrile illness; ALRI, acute lower respiratory infections; ASAL, arid and semi-arid land; CDC, Centers for Disease Control and Prevention; EFSA, European Food Safety Authority; ELISA, enzyme-linked immuno sorbent assay; FUO, fever of unknown origin; IFA, indirect immunofluorescence assay; $I H C$, immunohistochemistry; PCR, polymerase chain reaction; $R O C$, receiver operating characteristics; WHO, World Health Organization.
} 


\section{Acknowledgements}

We acknowledge the administration, clinicians and laboratory staff of the Garissa and Wajir hospitals for support during data and sample collection. We would like to thank R. Wehr and L. Nadin for the technical guidance and support. We thank Prof. Silke Fischer of the $\mathrm{Q}$ fever Consulting Laboratory Baden-Wurttemberg, State Health Office, Germany for support in IFA analysis of the samples. We are extremely grateful to the patients who participated in the study.

\section{Funding}

This study was funded and sponsored the German Academic Exchange Service (DAAD, grant no. A/12/97862), Friedrich-Loeffler-Institut, UK Medical Research Council, Natural Environment Research Council, Economic and Social Research Council, The Environmental \& Social Ecology of Human Infectious Diseases Initiative (ESEl, grant number 1100783/1), KEMRI, CGIAR Research Program for Agriculture for Nutrition and Health, led by IFPRI and German Ministry for Science and Education (grant number KI 1204). The funders had no role in study design, data collection and analysis, decision to publish, or preparation of the manuscript. This paper is published with the permission of Director, KEMRI.

\section{Availability of data and materials}

The data supporting the findings of this study is contained within the manuscript.

\section{Authors' contributions}

$\mathrm{JN}$ was involved in conception, design, data collection and analysis and drafted the manuscript. KH, MWP, RH, CF and HN were involved in conception, design, data analysis and coordination of the study. SK, and EF were involved in conception, study design, coordination and obtaining funding for the fieldwork. All authors contributed in writing of the manuscript and approved submission of the final manuscript.

\section{Competing interests}

The authors declare that they have no competing interests.

\section{Consent to publish}

Not applicable.

\section{Ethics and consent to participate}

The approval for collection of specimens from humans was obtained from the Scientific and Ethics Review Unit (SERU) of Kenya Medical Research Institute (KEMRI), protocol no. 2637. Permission to conduct the study was also sought from relevant public health offices and hospital administration. Written informed consent was obtained from every participant or from guardians of patients $<18$ years before specimen collection.

\section{Author details}

'Institute of Bacterial Infections and Zoonoses, Friedrich-Loeffler-Institut, 07743 Jena, Germany. ${ }^{2}$ Center for Infectious Diseases and Infection Control, Jena University Hospital, 07740 Jena, Germany. ${ }^{3}$ Centre for Microbiology Research (CMR), Kenya Medical Research Institute, P. O. Box 19464-00202, Nairobi, Kenya. ${ }^{4}$ Institute for Molecular Cell Biology, Center for Molecular Biomedicine, Friedrich Schiller University of Jena, 07745 Jena, Germany. ${ }^{5}$ Department of Medicine I, Division of Infectious Diseases and Tropical Medicine, Medical University of Vienna, 1090 Vienna, Austria. Institute of Infection and Global Health, University of Liverpool, Liverpool, UK. ${ }^{7}$ International Livestock Research Institute (ILRI), Road, P.O. Box 30709-00100, Nairobi, Kenya.

\section{Received: 5 January 2016 Accepted: 16 May 2016}

\section{Published online: 03 June 2016}

\section{References}

1. De Lange MM, Schimmer B, Vellema P, Hautvast JL, Schneeberger PM, Van Duijnhoven YT. Coxiella burnetii seroprevalence and risk factors in sheep farmers and farm residents in The Netherlands. Epidemiol Infect. 2014;142(6):1231-4.

2. EFSA. Scientific opinion on Q fever submitted to EFSA. EFSA J. 2010;8(5):1595.

3. Porter SR, Czaplicki G, Mainil J, Guattéo R, Saegerman C. Q Fever: current state of knowledge and perspectives of research of a neglected zoonosis. Int J Microbiol. 2011;2011:248418. doi:10.1155/2011/248418.
4. Schimmer $B$, Lenferink $A$, Schneeberger $P$, Aangenend $H$, Vellema $P$, Hautvast J, et al. Seroprevalence and risk factors for Coxiella burnetii ( $Q$ fever) seropositivity in dairy goat farmers' households in The Netherlands, 2009-2010. PLoS One. 2012;7(7):e42364.

5. Honarmand H. Q Fever: an old but still a poorly understood disease. Interdiscip Perspect Infect Dis. 2012;2012:131932. doi:10.1155/2012/131932.

6. de Rooij MM, Schimmer B, Versteeg B, Schneeberger P, Berends BR, Heederik D, et al. Risk factors of Coxiella burnetii ( $Q$ fever) seropositivity in veterinary medicine students. PLoS One. 2012;7(2):e32108.

7. Anderson A, Bijlmer H, Fournier PE, Graves S, Hartzell J, Kersh GJ, et al. Diagnosis and management of Q fever-United States, 2013: recommendations from CDC and the Q Fever Working Group. MMWR Recomm Rep. 2013;62(RR-03):1-30.

8. Maurin M, Raoult D. Q fever. Clin Microbiol Rev. 1999;12:518-53.

9. Dupont HT, Thirion X, Raoult D. Q fever serology: cutoff determination for microimmunofluorescence. Clin Diagn Lab Immunol. 1994;1(2):189-96.

10. Vanderburg S, Rubach MP, Halliday JE, Cleaveland S, Reddy EA, Crump JA Epidemiology of Coxiella burnetii infection in Africa: a OneHealth systematic review. PLoS Negl Trop Dis. 2014;8(4):e2787.

11. Dupont HT, Brouqui P, Faugere B, Raoult D. Prevalence of antibodies to Coxiella burnettii, Rickettsia conorii, and Rickettsia typhi in seven African countries. Clin Infect Dis. 1995;21(5):1126-33.

12. Dean AS, Bonfoh B, Kulo AE, Boukaya GA, Amidou M, Hattendorf J, et al, Epidemiology of brucellosis and q Fever in linked human and animal populations in northern Togo. PLoS One. 2013;8(8):e71501.

13. Schelling E, Diguimbaye C, Daoud S, Nicolet J, Boerlin P, Tanner M, et al. Brucellosis and Q-fever seroprevalences of nomadic pastoralists and their livestock in Chad. Prev Vet Med. 2003:61(4):279-93.

14. Montavon A, Jean-Richard V, Bechir M, Daugla DM, Abdoulaye M, Bongo RN, et al. Health of mobile pastoralists in the Sahel - assessment of 15 years of research and development. Trop Med Int Health. 2013;18(9):1044-52.

15. Muga GO, Onyango-Ouma W, Sang R, Affognon H. Sociocultural and Economic Dimensions of Rift Valley Fever. Am J Trop Med Hyg. 2015;92(4):730-8.

16. Crump JA, Morrissey AB, Nicholson WL, Massung RF, Stoddard RA, Galloway RL, et al. Etiology of Severe Non-malaria Febrile Illness in Northern Tanzania: A Prospective Cohort Study. PLoS Negl Trop Dis. 2013;7(7):e2324.

17. Knobel DL, Maina AN, Cutler SJ, Ogola E, Feikin DR, Junghae M, et al. Coxiella burnetii in humans, domestic ruminants, and ticks in rural western Kenya. Am J Trop Med Hyg. 2013;88(3):513-8.

18. Harris BP. Q-fever in Nairobi. East Afr Med J. 1952;29(4):128-30.

19. Craddock AL, Gear J. Q fever in Nakuru, Kenya. Lancet. 1955;269(6901):1167-9

20. Brotherston JC, Cooke ER. Q fever in Kenya. East Afr Med J. 1956;33(4):125-30

21. Vanek E, Thimm B. Q fever in Kenya. Serological investigations in man and domestic animals. East Afr Med J. 1976;53(12):678-84.

22. Potasman I, Rzotkiewicz S, Pick N, Keysary A. Outbreak of Q fever following a safari trip. Clin Infect Dis. 2000;30(1):214-5.

23. DePuy W, Benka V, Massey A, Deem S, Kinnaird M, O'Brien T, et al. Q Fever Risk Across a Dynamic, Heterogeneous Landscape in Laikipia County, Kenya. EcoHealth. 2014;11(3):429-33.

24. Hoek W, Sarge-Njie R, Herremans T, Chisnall T, Okebe J, Oriero E, et al. Short communication: prevalence of antibodies against Coxiella burnetii (Q fever) in children in The Gambia, West Africa. Trop Med Int Health. 2013;18(7):850-3.

25. Kobbe R, Kramme S, Kreuels B, Adjei S, Kreuzberg C, Panning M, et al. Q Fever in Young Children, Ghana. Emerg Infect Diseases. 2008;14(2):344-6.

26. Steinmann P, Bonfoh B, Peter O, Schelling E, Traore M, Zinsstag J. Seroprevalence of Q-fever in febrile individuals in Mali. Trop Med Int Health. 2005:10(6):612-7.

27. Kaabia N, Rolain JM, Khalifa M, Ben E, Bahri F, Raoult D, et al. Serologic study of rickettsioses among acute febrile patients in central Tunisia. Ann N Y Acad Sci. 2006;1078:176-9.

28. World Health Organization. IMAI district clinician manual: hospital care for adolescents and adults: guidelines for the management of illnesses with limited resources. Geneva: WHO; 2011. p. 1. ISBN: 978992974154828154821.

29. Reyburn H, Mbatia R, Drakeley C, Carneiro I, Mwakasungula E, Mwerinde O, et al. Overdiagnosis of malaria in patients with severe febrile illness in Tanzania: a prospective study. BMJ. 2004:329(7476):1212.

30. Kenya National Bureau of Statistics: Kenya Census 2009: http://www.knbs.or. ke/population-and-housing-census-2009. Accessed May 2015.

31. Kaindi DW, Schelling E, Wangoh JM, Imungi JK, Farah Z, Meile L. Risk factors for symptoms of gastrointestinal illness in rural town Isiolo, Kenya. Zoonoses Public Health. 2012;59(2):118-25. 
32. Ari MD, Guracha A, Fadeel MA, Njuguna C, Njenga MK, Kalani R, et al. Challenges of establishing the correct diagnosis of outbreaks of acute febrile illnesses in Africa: the case of a likely Brucella outbreak among nomadic pastoralists, northeast Kenya, March-July 2005. Am J Trop Med Hyg. 2011;85(5):909-12.

33. Nguku PM, Sharif SK, Mutonga D, Amwayi S, Omolo J, Mohammed O, et al. An Investigation of a Major Outbreak of Rift Valley Fever in Kenya: 2006-2007. Am J Trop Med Hyg. 2010;83(2):05-13.

34. Thiga JW, Mutai BK, Eyako WK. High Seroprevalence of Antibodies against Spotted Fever and Scrub Typhus Bacteria in Patients with Febrile IIIness, Kenya. Emerg Infect Diseases. 2015;21(4):688-91.

35. Klee S, Tyczka J, Ellerbrok H, Franz T, Linke S, Baljer G, et al. Highly sensitive real-time PCR for specific detection and quantification of Coxiella burnetii. BMC Microbiol. 2006;6(1):2. doi:10.1186/1471-2180-6-2.

36. Boden K, Brasche S, Straube E, Bischof W. Specific risk factors for contracting Q fever: lessons from the outbreak Jena. Int J Hyg Environ Health. 2014;217(1):110-5.

37. Hastie T, Tibshirani R, Friedman J. The Elements of Statistical Learning: Data Mining, Inference, and Prediction. 1st ed. New york: Springer; 2001.

38. León C, Ruiz-Santana S, Saavedra P, Almirante B, Nolla-Salas J, Álvarez-Lerma F, et al. A bedside scoring system ("Candida score") for early antifungal treatment in nonneutropenic critically ill patients with Candida colonization. Crit Care Med. 2006;34(3):730-7.

39. Schneeberger PM, Hermans MHA, van Hannen EJ, Schellekens JJA, Leenders ACAP, Wever PC. Real-Time PCR with Serum Samples Is Indispensable for Early Diagnosis of Acute Q Fever. Clin Vaccine Immunol. 2010;17(2):286-90.

40. Onchiri FM, Pavlinac PB, Singa BO, Naulikha JM, Odundo EA, Farquhar C, et al. Frequency and correlates of malaria over-treatment in areas of differing malaria transmission: a cross-sectional study in rural Western Kenya. Malar J. 2015;14:97. doi:10.1186/s12936-015-0613-7.

41. Juma E, Zurovac D. Changes in health workers' malaria diagnosis and treatment practices in Kenya. Malar J. 2011;10:1. doi:10.1186/1475-2875-10-1.

42. Mitema ES, Kikuvi GM. Surveillance of the overall use of antimicrobial drugs in humans over a 5 year period (1997-2001) in Kenya. J Antimicrob Chemother. 2004;54(5):966-7.

43. Prabhu M, Nicholson WL, Roche AJ, Kersh GJ, Fitzpatrick KA, Oliver LD, et al. Q fever, spotted fever group, and typhus group rickettsioses among hospitalized febrile patients in northern Tanzania. Clin Infect Dis. 2011;53(4):e8-15.

44. Kallander K, Nsungwa-Sabiiti J, Peterson S. Symptom overlap for malaria and pneumonia-policy implications for home management strategies. Acta Trop. 2004;90(2):211-4.

45. Ki-Zerbo GA, Tall F, Nagalo K, Ledru E, Durand G, Patey O. Rickettsiosis and Q fever in pyretic patients hospitalized at the Bobo-Dioulasso Hospital (Burkina Faso). Med Maladies Infect. 2000;30(5):270-4.

46. Ali-eldin F, Abdelhakam S, Ali-eldin Z. Clinical spectrum of fever of unknown origin among adult Egyptian patients admitted to Ain Shams University Hospitals: a hospital based study. J Egypt Soc Parasitol. 2011;41:379-86.

47. Vilibic-Cavlek T, Kucinar J, Ljubin-Sternak S, Kolaric B, Kaic B, LazaricStefanovic $L$, et al. Prevalence of Coxiella burnetii antibodies among febrile patients in Croatia, 2008-2010. Vector Borne Zoonotic Dis. 2012;12(4):293-6.

48. Khalili M, Shahabi-Nejad N, Golchin M. Q fever serology in febrile patients in southeast Iran. Trans R Soc Trop Med Hyg. 2010;104(9):623-4.

49. Metanat M, Sepehri RN, Alavi-Naini R, Shahreki S, Sharifi-Mood B, Akhavan A, et al. Acute Q fever among febrile patients in Zahedan, southeastern Iran. Turk J Med Sci. 2014;44(1):99-103.

50. McCaughey C, McKenna J, McKenna C, Coyle PV, O'Neill HJ, Wyatt DE, et al. Human seroprevalence to Coxiella burnetii (Q fever) in Northern Ireland. Zoonoses Public Health. 2008;55(4):189-94.

51. Luksic B, Punda-Polic V, Ivic I, Bradaric I, Bradaric N. Clinical and epidemiological features of hospitalized acute Q fever cases from SplitDalmatia County (Croatia), 1985-2002. Med Sci Monit. 2006;12(3):126-31.

52. Tissot Dupont H, Raoult D, Brouqui $P$, Janbon F, Peyramond D, Weiller PJ, et al. Epidemiologic features and clinical presentation of acute Q fever in hospitalized patients: 323 French cases. Am J Med. 1992;93(4):427-34.

53. Khan M, Coovadia YM, Connoly C, Sturm AW. The early diagnosis of typhoid fever prior to the Widal test and bacteriological culture results. Acta Trop. 1998;69(2):165-73.

54. Luxemburger C, Nosten F, Kyle DE, Kiricharoen L, Chongsuphajaisiddhi T, White NJ. Clinical features cannot predict a diagnosis of malaria or differentiate the infecting species in children living in an area of low transmission. Trans R Soc Trop Med Hyg. 1998;92(1):45-9.
55. Oster N, Krause E, Hatz C. Towards a rational malaria management at district hospital level: exploratory case series of febrile adult patients in a holoendemic area of Tanzania. Trop Doct. 2000;30(4):203-7.

56. Solera J, Martinez-Alfaro E, Espinosa A, Castillejos ML, Geijo P, RodriguezZapata M. Multivariate model for predicting relapse in human brucellosis. J Infect. 1998;36(1):85-92.

57. Noor AM, Kinyoki DK, Mundia CW, Kabaria CW, Mutua JW, Alegana VA, et al. The changing risk of Plasmodium falciparum malaria infection in Africa: 2000-2010: a spatial and temporal analysis of transmission intensity. Lancet. 2014;383(9930):1739-47.

58. Schlee G. Identities on the Move: Clanship and Pastoralism in Northern Kenya. Nairobi: Gideon Were Press; 1989.

59. Signs KA, Stobierski MG, Gandhi TN. Q fever cluster among raw milk drinkers in Michigan, 2011. Clin Infect Dis. 2012;55(10):1387-9.

60. Eldin C, Angelakis E, Renvoisé A, Raoult D. Coxiella burnetii DNA, But Not Viable Bacteria, in Dairy Products in France. Am J Trop Med Hyg. 2013;88(4):765-9.

61. Benson WW, Brock DW, Mather J. Serologic analysis of a penitentiary group using raw milk from a Q fever infected herd. Public Health Rep. 1963;78:707-71073.

62. Frangoulidis D, Schropfer E, Al Dahouk S, Tomaso H, Meyer H. Comparison of four commercially available assays for the detection of IgM phase II antibodies to Coxiella burnetii in the diagnosis of acute Q fever. Ann N Y Acad Sci. 2006:1078:561-2.

\section{Submit your next manuscript to BioMed Central and we will help you at every step:}

- We accept pre-submission inquiries

- Our selector tool helps you to find the most relevant journal

- We provide round the clock customer support

- Convenient online submission

- Thorough peer review

- Inclusion in PubMed and all major indexing services

- Maximum visibility for your research

Submit your manuscript at www.biomedcentral.com/submit
C Biomed Central 